\title{
Mounia Benalil et Janusz Przychodzen (dir.), Identités hybrides. Orient et orientalisme au Québec
}

Jean-François Plamondon

\section{(2) OpenEdition}

1 Journals

\section{Édition électronique}

URL : http://journals.openedition.org/studifrancesi/7756

DOI : ERREUR PDO dans /localdata/www-bin/Core/Core/Db/Db.class.php L.34 : SQLSTATE[HY000]

[2006] MySQL server has gone away

ISSN : 2427-5856

\section{Éditeur}

Rosenberg \& Sellier

Édition imprimée

Date de publication : 1 décembre 2009

Pagination : 681-682

ISSN : 0039-2944

\section{Référence électronique}

Jean-François Plamondon, « Mounia Benalil et Janusz Przychodzen (dir.), Identités hybrides. Orient et orientalisme au Québec », Studi Francesi [En ligne], 159 (LIII | III) | 2009, mis en ligne le 30 novembre 2015, consulté le 07 janvier 2021. URL : http://journals.openedition.org/studifrancesi/7756 ; DOI : https://doi.org/10.4000/studifrancesi.7756

Ce document a été généré automatiquement le 7 janvier 2021.

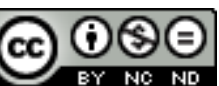

Studi Francesi è distribuita con Licenza Creative Commons Attribuzione - Non commerciale - Non opere derivate 4.0 Internazionale. 


\title{
Mounia Benalil et Janusz Przychodzen (dir.), Identités hybrides. Orient et orientalisme au Québec
}

\author{
Jean-François Plamondon
}

\section{RÉFÉRENCE}

MOUNIA BENALIL et JANUSZ PRZYCHODZEN (dir.), Identités hybrides. Orient et orientalisme au Québec, Montréal, Paragraphes, 2006, pp. 196.

En 1964, Sartre terminait son autobiographie par un aveu: il n'était somme toute qu'un homme comme tous les hommes et fait de tous les hommes. C'est un peu cette conclusion de l'unité englobant le multiple que nous retenons à la suite de la lecture des Identités hybrides. Orient et orientalismes au Québec. Le projet, loin de nous convaincre au départ, a pourtant su nous charmer et même nous convaincre que l'orientalisme a toujours accompagné l'âme québécoise comme une partie de soi, qui marchait à côté de soi. Si, à notre avis, un KRIEGHOFF aurait pu nuancer les propos de Chukhivich sur l'art orientalisant au Québec, le thème est de toute évidence présent à toutes les époques et subit une évolution plus qu'intéressante. сникніvicH a raison de rappeler que même les peintres de la modernité, Borduas le premier, se sont aussi nourris à l'auge d'un imaginaire où l'Orient se pose sur les toiles comme une ombre d'un nouvel Occident. Pour sa part, Serge GRANGER, défait le mythe d'un Québec fermé sur lui-même avant la Révolution tranquille (1960) et rappelle à juste titre que dès le XvII esiècle, les écrits québécois se préoccupent de l'évolution de la Chine et de l'Orient. Que ce soit des écrits sur les missionnaires en Chine, au Japon ou en Indes; que ce soit les tentatives de Charlevoix d'expliquer l'origine des peuples amérindiens, l'orient, terre que l'on cherchait en découvrant le Nouveau Monde, ne pouvait pas disparaitre des imaginaires en quête identitaire. Faut-il rappeler aussi la fascination de la Chine pour les grands hommes de la modernité québécoise. Alain Grandbois, qui publie son premier recueil de 
poésie à Hankéou, est sans doute, parmi les modernes attirés par un Orient mystérieux, l'exemple le plus cité. Granger rappelle aussi que c'est René Lévesque (premierministre du Québec de 1976 à 1985) qui narre le tout premier film de fiction sonore québécois (1943) dont l'action se déroule en Mandchourie.

En regardant alter c'est souvent ego qui se découvre et se comprend mieux. L'analyse de Vijaya RAO montre que ce «qui est intéressant dans le corpus québécois, contrairement aux textes européens orientalistes, c'est l'identification à la victime, le faible ou le protagoniste hésitant» (p. 71), et les textes analysés d'Yvon RIVARD et de Larry TREMBLAY ne semblent pas faire exception à la règle. Le Chinatown est ensuite lu par Gilles DUPUIS comme un espace gigogne, une ville dans la ville. En prolongeant son propos, Dupuis en vient à se demander si la littérature québécoise n'aurait pas perdu le nord et gagné un orient, "comme semble l'indiquer la diversification des écritures migrantes venues d'Asie (Chen, Chung, Shimazaki) mais aussi un certain engouement occidental pour l'Extrême-Orient (Parent, Amyot), ou, au contraire, si elle est sur le point de se réorienter par le biais d'une forme de contamination avec l'Autre, en l'occurrence l'autre asiatique» (p. 90). De concert avec Dupuis, on peut se demander si, après un début de $\mathrm{xx}^{\mathrm{e}}$ siècle marqué du sceau de l'exotisme et une fin du même siècle chanté sous le signe des écritures migrantes, le temps ne serait pas venu d'analyser l'autre comme une composante de soi. Parce que si l'Orient est un concept spatial poreux ou perméable, il est aussi marqué par le temps. Et l'imaginaire, depuis peut-être les Mille et une nuits, nous amène à marquer l'Orient d'un temps abstrait qui n'est pas le nôtre. En analysant l'œuvre de Naim Kattan, Anne CAUMARTIN avance que la rupture temporelle se voit, en Occident, dans la façon même d'aborder l'espace» (p.120). C'est aussi un espace autre que l'on découvre avec Rachel BOUvet qui analyse le roman Hypatie ou la fin des dieux de Jean Marcel. Sa lecture nous plonge dans un espace oriental avant même qu'il ne soit véritablement nommé comme tel, à une époque où le paganisme et le sacré se disputaient des héros dont les identités sont parfois très proches l'une de l'autre.

L'identitaire comme filon de la littérature québécoise? Pourquoi pas. Après tout n'étaitce pas pour enraciner l'identité que les romans québécois, en tout premier lieu, se sont donnés avec force et excès au terroir. La première querelle littéraire au Québec n'étaitelle pas entre les exotiques et les régionalistes? Certes, mais on a longtemps vu l'exil comme l'archétype du thème littéraire québécois. Le tandem «exil et identité», au fond, n'est peut-être que l'autre face du binôme "éphémère et permanence», comme l'ipséité est une composante de la mêmeté. Chose certaine, le tandem plaît au Québec, comme si l'exil des autres informait sur l'identité de soi. N'est-ce pas d'ailleurs la conclusion à laquelle arrive Johann SADOCK après avoir analysé des textes d'auteurs qui ont traversé monts et vaux pour rencontrer un Alter québécois, quoique proche d'Ego, jamais le même. «Chez Robin comme chez Kattan et Teboul, des jeux de miroir, certains reflets entre Québec et Orient à la surface des stratégies plus conscientes d'identification rappellent et permettent d'oublier, momentanément, qu'on est en exil» (p. 159). Alter au miroir d'Ego, comme l'homme sartrien fait de tous les hommes. 